Elsevier required licence: (C) $<2020>$. This manuscript version is made available under the CC-BY-NCND 4.0 license http://creativecommons.org/licenses/by-nc-nd/4.0/

The definitive publisher version is available online at

[https://www.sciencedirect.com/science/article/abs/pii/S0011916420313904?via\%3Dihub] 


\section{Conceptual Design of a Dynamic Turbospacer for Efficient Low Pressure}

\section{Membrane Filtration}

Syed Muztuza Ali ${ }^{\mathrm{a} 1}$, Adnan Qamar ${ }^{\mathrm{b} 1}$, Sherub Phuntsho ${ }^{\mathrm{a}}$, Noreddine Ghaffour ${ }^{\mathrm{b}}$, Johannes S. Vrouwenvelder $^{\mathrm{b}}$, Ho Kyong Shon ${ }^{\mathrm{a} *}$

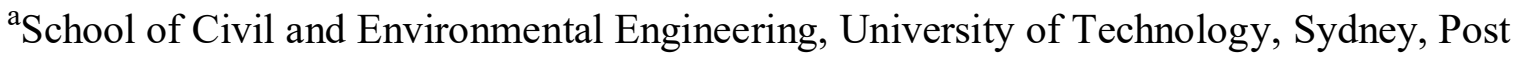
Box 129, Broadway, NSW 2007, Australia.

${ }^{b}$ King Abdullah University of Science and Technology (KAUST), Water Desalination and Reuse Center (WDRC), Biological and Environmental Science and Engineering (BESE), Thuwal 23955-6900, Saudi Arabia

Desalination

06 August 2020

* Corresponding authors: Tel.:(+61) 029514 2629; email: Hokyong.Shon-1@uts.edu.au 1 S.M. Ali and A. Qamar equally contributed to this work 


\section{Abstract}

2 This study presented a conceptual design of a novel dynamic turbospacer to enhance the

3 performance of a low pressure membrane filtration process. It consists of ladder type filaments

4 and a series of microturbine networks within the filament cells. The rotation of the turbines

5 leads to the formation of turbulence in the feed channel that prevents foulants accumulation.

6 Direct numerical simulation (DNS) was conducted to characterize the fluid flow behaviors of

7 the feed channel for the proposed turbospacer and compared with a standard symmetric non-

8 woven feed spacer. Further, their performances were investigated for a low pressure

9 ultrafiltration (UF) process in a lab-scale experimental setup using $2.8 \mathrm{~mm}$ thick 3D printed prototypes of the turbospacer and the standard spacer. Experiments for the proof of this concept were conducted at $173 \mathrm{~mL} / \mathrm{min}$ and $250 \mathrm{~mL} / \mathrm{min}$ feed solution inlet velocity when Reynolds number of the flow is 160 and 230 respectively. Substantial reductions in fouling effects using the turbospacer was confirmed by the in-situ Optical Coherence Tomography (OCT) scans of the fouling cake layer accumulated over the membrane during the filtration of seawater with high fouling potential. The proposed turbospacer also lowered the average pressure drop by 4 times and enhanced the specific permeate flux by more than 3 times at $173 \mathrm{~mL} / \mathrm{min}$ inlet flowratre. At the same operating condition, the specific energy consumption for the turbospacer was found about 2.5 folds lower than the standard spacer.

\section{Keywords}

Feed Spacer Design; Membrane Filtration; 3D Printing; DNS; Fouling; Optical coherence tomography (OCT) 


\section{Introduction}

Membrane desalination has emerged as a promising technology to satisfy the growing demand for clean freshwater by recovering water from unconventional sources such as seawater [1-3]. Ultrafiltration (UF) is one of the most widely used low-pressure membrane filtration technology for the pretreatment of membrane based seawater desalination. It removes particulate matters, organic/inorganic compounds, and micro-organisms from the feed seawater to ensure the stable operation of the desalination system. Therefore, this process is highly susceptible to fouling effects, as the foulants accumulate on the ultrafiltration membrane and in the feed channel [4-6]. It increases the pressure drop across the feed channel and reduces the water permeation through the membrane, which results in limiting the process performance. However, as unsteady flow inside the membrane channel hinders the growth of the foulants [710], filtration modules employ a feed spacer to separate the membrane sheets and aim to generate fluid flow unsteadiness [11-13]. Therefore, the design of feed spacers plays a crucial role in the efficient operation of low pressure membrane filtration processes.

Numerous research articles presented the enhancement of fluid unsteadiness by modifying the filament shape, arrangement, spacing, and thickness of the net type conventional feed spacer [14-18]. However, the main limitation of these spacers lies in its unsteadiness/turbulence production at filtration operating conditions (typically $\sim 0.16 \mathrm{~m} / \mathrm{s}$ feed velocity) [7, 19]. Depending on feed velocity (or Reynolds number) flow transition is triggered from steady to unsteady state due to vortex separation mechanism $[7,10,20,21]$. This transition is known to occur at relatively high crossflow velocity (much greater than $0.16 \mathrm{~m} / \mathrm{s}$ ), as the very small clearance between the membrane and filament constrains the separation of boundary layer [19, 22]. In addition, high shear stress and velocity are only produced in the constriction zone of the spacer, while the major portion of the membrane surface has low shear stress. Further, the drag force produced due to the spacer filaments results in a significant pressure drop across the 
channel which increases the specific energy consumption of the processes [22].

Some attempts to modify the spacer design to change the mechanism of fluid unsteadiness/turbulence generation resulted in the development of helical micro-structured type spacer [23], perforated spacers [24], triply periodic minimal surfaces (TPMS) spacer [25] and symmetric helical filaments [26]. These spacers increased the fluid unsteadiness, but the pressure drop can be further reduced. A column type feed spacer with thinner filament substantially reduced the pressure drop significantly but with the expense of a reduction in fluid unsteadiness [27]. In another study, a hairy type spacer was proposed for a drastic reduction in pressure drop [28]. But, the maximum oscillation of the fibers was only $\pm 0.05^{\circ}$. In contrast, a rotating object in the feed channel may reduce the pressure drop as it lowers the drag force compared to any stationary object and increases the flow turbulence as well.

This proof of concept study aims to explore a novel design of feed spacer to improve the performance of a low pressure membrane process by minimizing the fouling effects through the creation of turbulent fluid flow and significant pressure drop reduction. This spacer is designed by adding a network of microturbines within the filament cells of a ladder type feed spacer. The proposed spacer is termed as "turbospacer" in this study. Boxed in the sufficiently large rectangular flow channels, microturbines were designed within the transverse filaments material and manufacturing technology, it may be applied in other module configurations in 
technology and the rotational speed of the turbines inside the membrane module at different inlet velocities was measured employing a high-speed camera, which influences the performance and fluid flow through the spacer-filled channel. Direct numerical simulation (DNS) was conducted to computationally investigate the fluid flow behavior in the feed channel using the turbospacer and compared with a standard symmetric non-woven spacer design of the same thickness which served as a reference for the comparison at the same operating conditions. After the theoretical analysis, performance of the turbospacer and the standard spacer in terms of foulants accumulation on the membrane, pressure drop across the channel, specific flux, and specific energy consumption were experimentally investigated in a lab-scale UF setup for the seawater filtration using a feed solution synthesized by mixing sodium alginate and Xanthan gum with microbes incubated real seawater.

\section{Materials and Methodology}

\subsection{Design of the conceptual turbospacer and the standard spacer}

The proposed turbospacer and standard symmetric non-woven spacer were designed using a commercial computer aided design (CAD) software CATIA (Dassault Systems, France). Table 1 compares the CAD design of the spacers with their major dimensions. The turbospacer consists of rectangular filaments arranged in a ladder type structure. The conceptual turbospacer was designed $2.8 \mathrm{~mm}$ thick in this study. It is very common to design spacers thicker than $2 \mathrm{~mm}$ for the lab-scale proof of concept studies as the commercial feed spacer thickness for filtration module varies from $22 \mathrm{mil}(0.56 \mathrm{~mm})$ to $120 \mathrm{mil}(3 \mathrm{~mm})$ [29]. For example, thickness of the microstructured helical spacer, zigzag spacer, and sawtooth spacer was $4 \mathrm{~mm}[30,31]$. In another study, the thickness of a static mixing spacer was $3 \mathrm{~mm}$ [32]. However, a $2 \mathrm{~mm} \times 2.8 \mathrm{~mm}$ opening was designed over each filament (can be seen in the top and front view as shown in Table 1) of the turbospacer. 
Table 1 CAD design and 3D printed prototypes of the standard spacer and turbospacer.

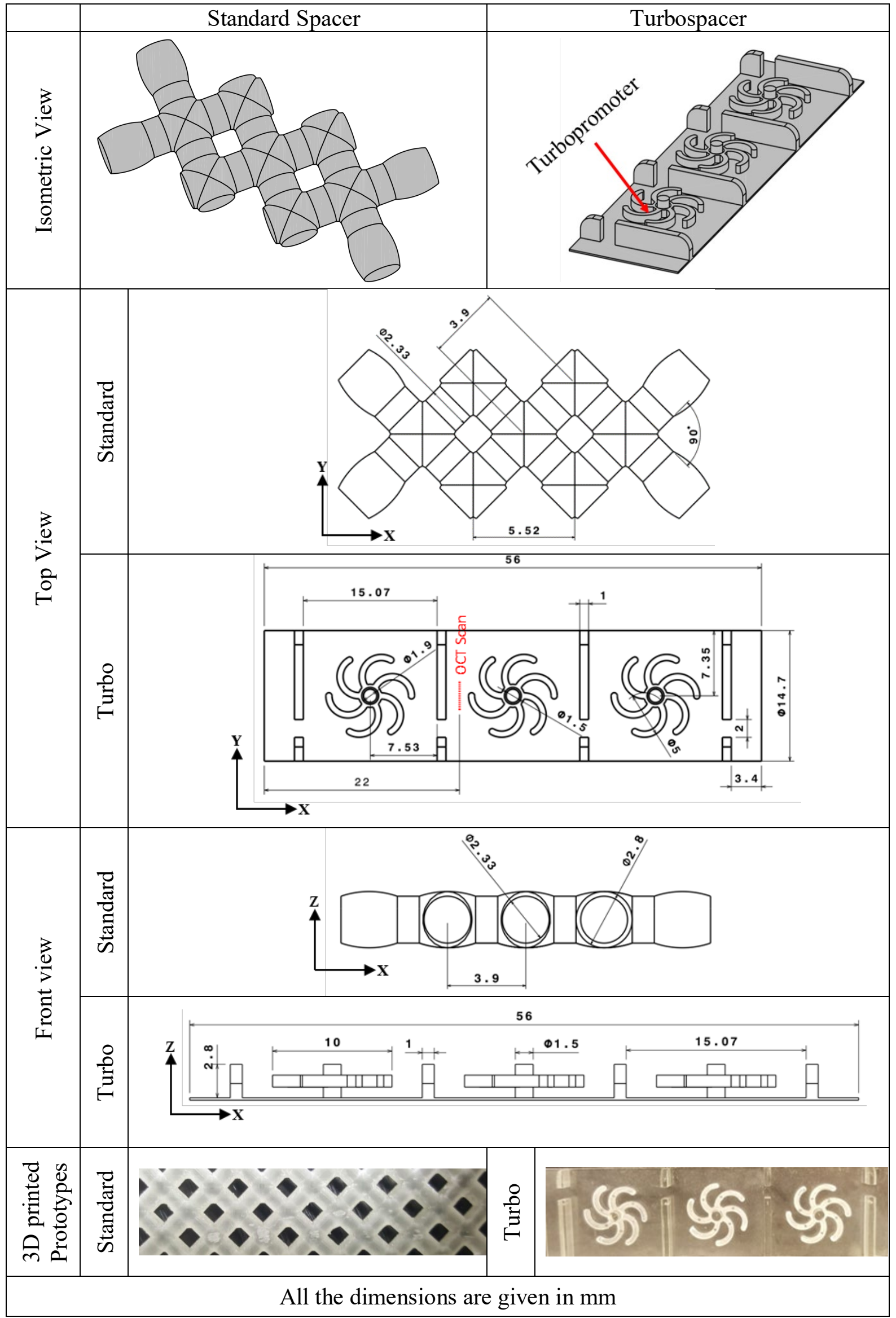


100 Each filament cell also contains a turbine shaped rotor installed around a cylindrical shaft at 101 the centroid that holds the turbines at a fixed location and also supports the membrane. Because of this additional membrane support, the filament spacing is almost double for the turbospacer, which helps in further reducing pressure drop for this spacer. Moreover, there is a clearance of $0.4 \mathrm{~mm}$ between the inner diameter of the rotors $(1.9 \mathrm{~mm})$ and the outer diameter of the shaft $(1.5 \mathrm{~mm})$. Due to this clearance, when the feed solution micro-jets strike the rotor blades the turbines rotate around the shaft. The thickness of these rotors was $1 \mathrm{~mm}$ which was about three times thinner than the feed channel height so that the rotors can rotate freely inside the channel. Another standard non-woven symmetric spacer of equal thickness was designed to serve as a benchmark for the performance comparison of the turbospacer developed in this study. The standard spacer consists of cylindrical filaments arranged in diamond shaped structure as shown in Table 1. Maintaining the same thickness with the turbospacer, the standard spacer (D) is designed $2.8 \mathrm{~mm}$ thick. Moreover, the diameter of the filament (d) is $2.33 \mathrm{~mm}$ which is selected based on the same clearance ratio $(d / D=0.83)$ with the reference spacers used in the previous studies [24, 27]. Thickness of the reference spacer from our previous studies was 1.2 mm (47 mil) which is also widely used in filtration module (for example 47 mil feed spacer for microdyn-Nadir turboclean element, 47 mil medium foulant spacer for Sterlitec). However, since the diameter of the standard spacer used in this study was different from the previous spacers, a non-dimensional Reynolds number was employed to select the crossflow velocity. Selection of the crossflow velocity for the experiments is discussed in detail in section 2.3. Finally, these CAD designs were used to develop the prototypes of the turbospacer and standard spacers by employing a DLP (Digital light processing) 3D printer (Miicraft 125, Rays Optics Inc., Hsinchu, Taiwan). Both the spacers were fabricated sufficiently larger than the filtration channel of the experimental setup $(60 \mathrm{~mm} \times 15 \mathrm{~mm})$ and were cut into the required size before the experiments. 


\subsection{Numerical Analysis}

126 Fluid flow behavior of feed channel was computationally simulated and compared for the proposed turbospacer and standard spacer at two different feed inlet velocities as used in the experiments. The hydrodynamics for turbospacer primarily depends on the blade rotation speed. Therefore, the rotational speed was experimentally measured for different feed velocities using a high-speed camera. The obtained rotational speed was used as an input in the DNS simulations. The experimental setup employed to measure the rotational speeds is described in Fig. S1 of the supplementary information.

In the present study, DNS technique was utilized to solve the conservation equation. Although high-grid resolutions are required to perform DNS, it has the advantage that no turbulence model is required as the smallest flow scales (up to Kolmogorov scale) are resolved in these types of simulations [33]. Further, DNS is inherently unsteady so no prior assumption about the state of the fluid is required. Therefore, the spatial and temporal accuracy of the DNS technique is much higher as compared to the other methods utilized in fluid-flow simulations. Considering feed as an incompressible Newtonian fluid, the governing equations (mass and momentum conservation equations) are given by:

$\rho\left(\frac{\delta \boldsymbol{u}}{\delta t}+(\boldsymbol{u} . \boldsymbol{\nabla}) \boldsymbol{u}\right)=-\boldsymbol{\nabla} p+\mu \boldsymbol{\nabla}^{2} \boldsymbol{u}+\rho g$

where $t$ is time (s), $\boldsymbol{u}$ is the velocity $(\mathrm{m} / \mathrm{s})$ vector, $p$ is the pressure $\left(\mathrm{N} / \mathrm{m}^{2}\right)$ and $\boldsymbol{\nabla}$ represents the spatial gradient. In addition, $\rho$ and $g$ represent the density $\left(998 \mathrm{~kg} / \mathrm{m}^{3}\right)$ of the feed fluid and the acceleration due to gravity $\left(9.81 \mathrm{~m} / \mathrm{s}^{2}\right)$, respectively.

For standard spacer at the inlet boundary, average velocity corresponding to the experimental condition was used. The membrane surface was considered as a rigid wall [19, 22, 34, 35]. Periodic boundary conditions were specified along the span-wise direction (Y-axis) and at the outlet pressure condition was specified. For turbospacer, velocity inlet condition was specified 
at the inlet face and pressure outlet condition was specified at the outlet face. Remaining boundaries were treated as walls with no-slip boundary conditions.

The cut-cell meshing approach was utilized for meshing the fluid volume $[24,36]$. In this approach majority of the discretized control volumes are hexahedrons except for a few layers of tetrahedrons near the solid boundaries. This ensures a low grid aspect ratio resulting in improved convergence and higher accuracy when compared to a mesh made of tetrahedrons only. For the case of turbospacer, which involves moving components, the overset technique was utilized. Here the rotating component has separate meshing, which is immersed in a background fixed mesh [36]. For all time, the background mesh is fixed and the rotating mesh is updated at each time step taking into account the turbospacer rotation (rotational speed was obtained by high-speed camera as explained in Fig. S1 and S2 in the supplementary information).

Using the above specified boundary conditions, the system of Eqs. (1) and (2) was solved on the commercial solver ANSYS Fluent. The spatial and temporal discretizations were second order accurate [37] with PISO scheme [36]. A mesh independence study was first performed and mesh $\sim 10$ million points for the standard spacer and $\sim 25$ million for turbospacer was selected, which accurately resolve the flow field. The discretized system of equation was quite large, therefore, computations were performed on in-house supercomputing facility (Shaheen II) using 2000 core for $\sim 48$ hours for the standard spacer and $\sim 200$ hours for turbospacer, respectively. The validation and accuracy of the DNS solution method have been already demonstrated in previous work [19].

\subsection{Experimental setup and operating conditions}

172 The rotational speed of the microturbine blades was experimentally measured by using a high-

173 speed camera to analyze the flow pattern in the channel. One of the six blades of the 3D printed turbospacer was painted red to distinguish it from others. Then the turbospacer was assembled 
in a crossflow filtration test cell over a UF membrane, as shown in the schematic diagram of the high-speed camera setup in Fig. S1 of the supplementary section. Water was circulated through the cell at different velocities from $40 \mathrm{~mL} / \mathrm{min}$ to $330 \mathrm{~mL} / \mathrm{min}$. Rotation of the blades at these velocities was recorded at 7000 frames per second using the high-speed camera (Phantom V1212) at an image resolution of $1280 \times 800$ pixels. After analyzing the recorded videos, time (in microsecond) required for one revolution of the blade was determined which provided the rotating speed in rpm. Rotational speed at different velocities is reported in Fig. $\mathrm{S} 2$ in the supplementary section. Further, performance of the spacers was experimentally investigated using a typical lab-scale filtration setup with permeate production, simulating crossflow membrane process. The schematic of the filtration setup is given in Fig. S3 of the supplementary information. The experimental setup consists of a feed solution circulation pump, a feed solution tank, a permeate collection tank, a membrane test cell, and a data acquisition system. Feed channel dimension of the test cell was $60 \mathrm{~mm} \times 15 \mathrm{~mm} \times 2.8 \mathrm{~mm}$. In addition, $150 \mathrm{kDa}$ UF membranes were used for all the experiments of this study (Detailed specification of the membrane is provided in Table $\mathrm{S} 1$ of supplementary section). This setup was also devised with a flowmeter, two pressure sensors, and an electronic weight balance. The weight balance measured the permeate production at a regular period of interval (1 minute). These sensors also transmitted their dataset to a computer connected to the setup using a data acquisition system for further analysis. Finally, Optical Coherence Tomography (OCT) technique was employed for the capturing of the in-situ images of the foulants layer deposited over the membrane at the end of the filtration experiment (after $48 \mathrm{~h}$ ) [38, 39]. OCT images were recorded at the same location $(22 \mathrm{~mm}$ from the feed solution inlet and at the center in the span wise direction of both spacers) over the membrane for the spacers as shown in the top view of the turbopromter in Table 1. Specifications of all the components and the sensors are described in Table S1 of the supplementary information. 
Usually, performance of the spacers is characterized by the permeate flux of the filtration system [30, 40]. This study compared the transient normalized flux through the membrane using both turbospacer and the standard spacer, which is a ratio of the instantaneous flux $\left(J_{w}\right)$ and the initial flux $\left(J_{w 0}\right)$ during the filtration experiment. But the spacer performance should be evaluated by a term that combines both feed channel pressure drop and permeate flux [26, 27]. In this study, the spacer performance was compared in terms of specific flux and specific energy consumption, which are the functions of permeate flux and pressure drop across the test cell. Specific water flux is given by [26, 27],

$$
J_{w}^{s}=\frac{J_{w}}{\Delta P_{c e l l}}
$$

where $J_{w}$ is the water flux through the membrane $(\mathrm{LMH})$ and $\Delta P_{\text {cell }}$ represents the pressure drop across the test cell length (mbar). Specific energy consumption (SEC) is another 210 important performance parameter used for the comparison of different spacer designs [27], which is expressed by Eq. (4).

$$
S E C=\frac{E}{Q_{p}}
$$

212 here, $E$ denotes the amount of energy $(\mathrm{kWh})$ consumed by the system and $Q_{p}$ is the rate of

213 permeate production $\left(\mathrm{m}^{3} / \mathrm{h}\right)$. However, excluding any hydraulic resistance in the tubings of the

214 experimental setup, the energy consumption of the filtration system accounting only for the spacers used in the channel is defined by [27],

$$
E=\frac{1.67 E-9 \times Q_{F} \times \Delta P_{\text {cell }}}{\eta}
$$

216 where $Q_{F}$ represents the feed inlet flowrate $(\mathrm{mL} / \mathrm{min})$ and $\eta$ is the pump efficiency (\%).

217 Derivation of equation (5) is provided in the supplementary section.

218 Feed solution inlet velocity is a major operating condition that influences the performance of 219 the spacer significantly. The typical crossflow velocity for the membrane filtration applications 
is $0.16 \mathrm{~m} / \mathrm{s}[24,27]$. Therefore, to generate flow similarity using the current $2.8 \mathrm{~mm}$ thick symmetric spacer, a non-dimensional Reynolds number is used to calculate the crossflow velocity, At $0.16 \mathrm{~m} / \mathrm{s}$ feed solution velocity, Reynolds number is 160 for the $1.2 \mathrm{~mm}$ thick spacer as the diameter of the filament is $1 \mathrm{~mm}$. For the same Reynolds number, the crossflow velocity is $0.07 \mathrm{~m} / \mathrm{s}$, when the standard spacer proposed in this study $(2.88 \mathrm{~mm}$ thick) is used. Therefore, the crossflow velocity in this study is about 2.3 times lower than the typical operating velocity for the $1.2 \mathrm{~mm}$ spacer. However, experiments were also conducted at a velocity of $0.10 \mathrm{~m} / \mathrm{s}$ to study the effects of feed solution inlet velocity on the turbospacer and the spacer performances when the Reynolds number was 230 . But, due to the rotation of the turbine blades, inlet velocity to the channel for the turbospacer was significantly different from the standard spacer. Therefore, performances of the spacers were not compared at the same feed solution inlet velocities rather the performances were compared for the same inlet flowrates. Feed solution inlet flowrates corresponding to $0.07 \mathrm{~m} / \mathrm{s}$ and $0.10 \mathrm{~m} / \mathrm{s}$ inlet velocities are $173 \mathrm{~mL} / \mathrm{min}$ and $250 \mathrm{~mL} / \mathrm{min}$, respectively.

\subsection{Synthesis of feed solution}

Total $2 \mathrm{~L}$ of feed solution was synthesized to stimulate fouling growth in a faster manner for some short term (48 h) experiments to compare the filtration performance and fouling effects using the proposed turbospacer and the standard spacer. $0.5 \mathrm{~g} / \mathrm{L}$ of Bacto ${ }^{\mathrm{TM}}$ Yeast was first added with $0.5 \mathrm{~L}$ seawater as a source of nutrient for the microbes that exist in the seawater and incubated for $24 \mathrm{~h}$ at $30^{\circ} \mathrm{C} .0 .25 \mathrm{~g} / \mathrm{L}$ of xanthan gum (Sigma-Aldrich) and $0.1 \mathrm{~g} / \mathrm{L}$ of sodium alginate (Sigma-Aldrich) were added to the remaining 1.5 L seawater. Xanthan gum in the solution is a type of polysaccharide that works as an organic foulant. In contrast, sodium alginate is another polysaccharide that is extracted from the cell walls of brown algae. It does not only represent the organic foulants in the seawater but also works as a biofoulant in the 
solution. Finally, the $0.5 \mathrm{~L}$ incubated seawater and the remaining $1.5 \mathrm{~L}$ seawater were mixed and stirred for $4 \mathrm{~h}$ before the experiments.

\section{3. Results and discussion}

247 Fluid flows of the feed channel filled with the standard and the proposed turbospacer were first numerically simulated to explain the role of hydrodynamics at an elemental level occurring inside the filament cell. After that filtration performances of the standard spacer and turbospacer were experimentally studied in terms of fouling effects, pressure drop, specific flux, and specific energy consumption for the filtration of seawater using a lab-scale UF setup.

\subsection{Hydrodynamic behaviors of feed channel flow}

The DNS computations were performed at two different feed solution inlet flowrates of 173 $\mathrm{mL} / \mathrm{min}$ and $250 \mathrm{~mL} / \mathrm{min}$ for both spacers. Turbospacer inlet velocities to the filament cell were computed as $0.6 \mathrm{~m} / \mathrm{s}$ (turbine rotation speed, $355 \mathrm{rpm}$ ) and $0.74 \mathrm{~m} / \mathrm{s}$ (turbine rotation speed, $485 \mathrm{rpm}$ ), while for standard spacer they were $0.07 \mathrm{~m} / \mathrm{s}$ and $0.1 \mathrm{~m} / \mathrm{s}$ corresponding to 173 $\mathrm{mL} / \mathrm{min}$ and $250 \mathrm{~mL} / \mathrm{min}$ flowrates, respectively. For the turbospacer, a single cell was only computed while for the standard spacer 2 cells with two half cells were simulated to properly resolve the flow dynamics $[21,26]$. Fig. 1 shows the variation in velocity magnitude at quasisteady state $(\sim \mathrm{t}=0.2$ seconds $)$ at three planes $(\mathrm{Z}=1.4 \mathrm{~mm}, 0.7 \mathrm{~mm}$ and $0.1 \mathrm{~mm})$ inside the turbospacer cell for $173 \mathrm{~mL} / \mathrm{min}$ and $250 \mathrm{~mL} / \mathrm{min}$ inlet velocities. At the initial stages (refer to the attached movie) when the blades just start their movement, the high velocity regions are around the central plane of the channel. 

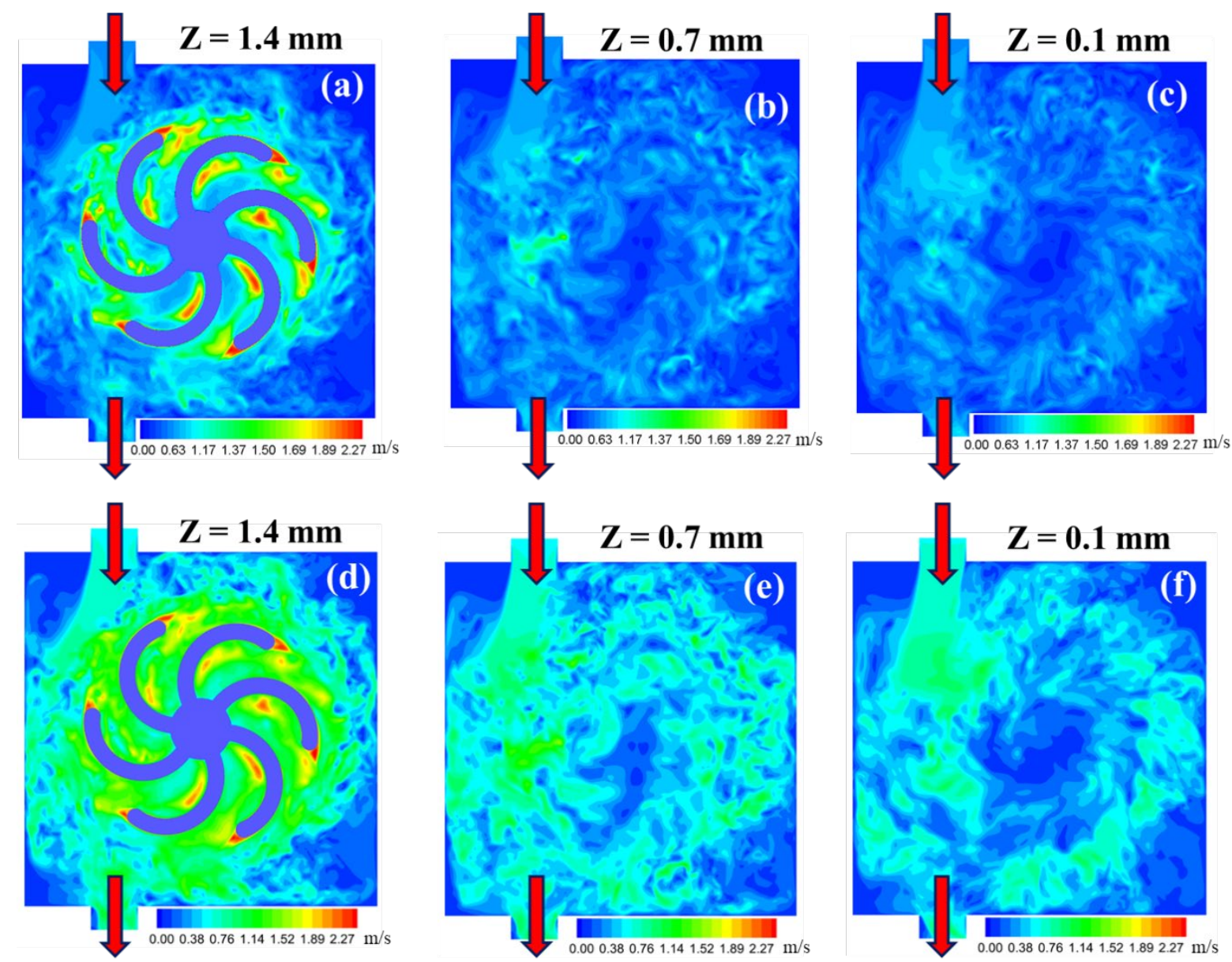

Fig. 1. Numerically simulated velocity magnitude at various locations along the height of the channel for turbospacer at two different inlet flowrates. Top row is for $Q_{F}=173 \mathrm{~mL} / \mathrm{min}$ at (a) $\mathrm{Z}=1.4 \mathrm{~mm}$, (b) $\mathrm{Z}=0.7 \mathrm{~mm}$, (c) $\mathrm{Z}=0.1 \mathrm{~mm}$ height and bottom row is for $Q_{F}=$ $250 \mathrm{~mL} / \mathrm{min}$ at (d) $\mathrm{Z}=1.4 \mathrm{~mm}$, (e) $\mathrm{Z}=0.7 \mathrm{~mm}$, (f) $\mathrm{Z}=0.1 \mathrm{~mm}$. Due to the rotation of the turbines (355 rpm and $485 \mathrm{rpm}$ ), fluid enters the filament cell at $0.6 \mathrm{~m} / \mathrm{s}$ and $0.74 \mathrm{~m} / \mathrm{s}$. Arrow heads on the figure show the inlet and outlet of fluid. Fluid flow unsteadiness is clear in the figures.

Roughly more than three times rise in velocity magnitude is observed (maximum velocity achieved is $2.27 \mathrm{~m} / \mathrm{s}$ ) compared to plane close to the bottom wall (membrane). As the rotation of the turbine is quite fast, the fluid region surrounds the blades pick larger velocity. Further, the outburst to unsteady state occurs very quickly (see the attached movie) and flow is highly 


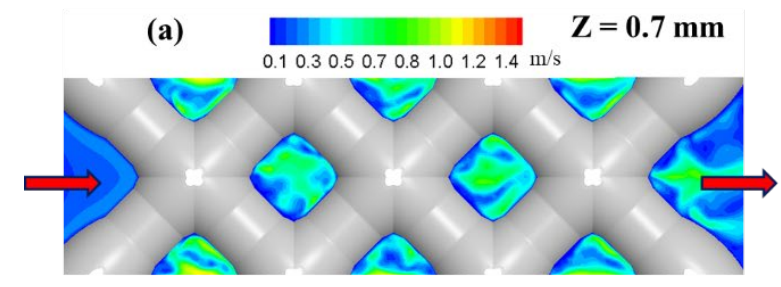

(b)

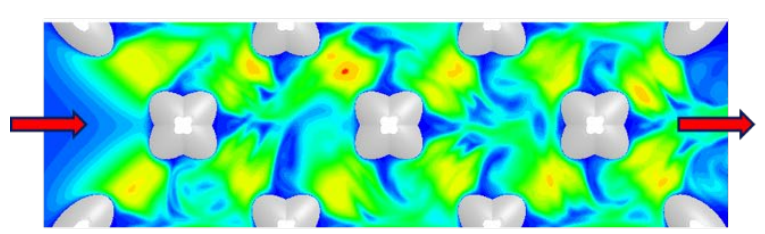

(c)
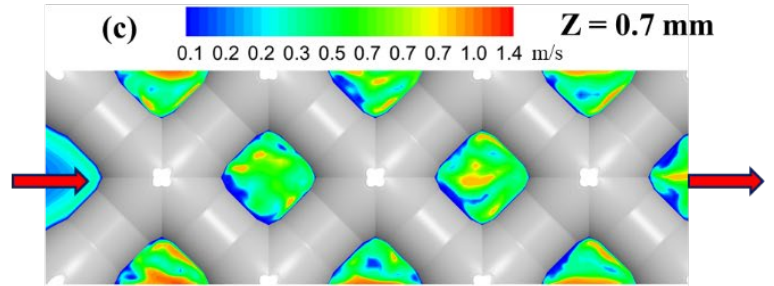

(d)

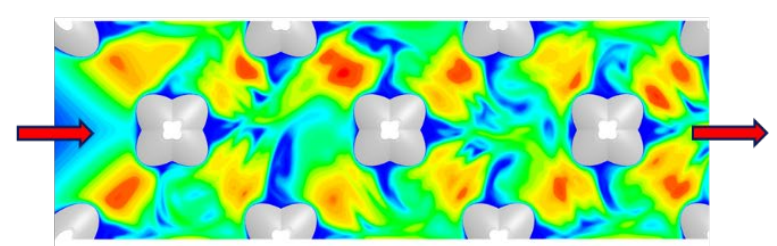

282

283

Fig. 2. Theoretically estimated velocity magnitude variation along the depth of channel for standard spacer at $Q_{F}=173 \mathrm{~mL} / \mathrm{min}$ and $250 \mathrm{~mL} / \mathrm{min}$. Left column represents the spatial distribution of fluid velocity for $Q_{F}=173 \mathrm{~mL} / \mathrm{min}$ at (a) $\mathrm{Z}=0.7 \mathrm{~mm}$, (b) $\mathrm{Z}=0.1 \mathrm{~mm}$ height whereas right column stands for $Q_{F}=250 \mathrm{~mL} / \mathrm{min}$ at (c) $\mathrm{Z}=0.7 \mathrm{~mm}$, (d) $\mathrm{Z}=0.1 \mathrm{~mm}$. Color bar on the figure explains the distribution of velocity magnitude.

For the case of standard spacer, velocity magnitudes are presented at two planes $(Z=0.7 \mathrm{~mm}$ and $0.1 \mathrm{~mm}$ ) inside the computational domain as depicted in Fig. 2 for both flowrates. As seen clearly for both cases, the flow is unsteady with level of unsteadiness and is slightly higher for 250 inlet flowrate. The highest velocity magnitude is observed under the filaments (at the constriction zone), whereas the lowest velocity regions are behind the filament or the filament intersections. Therefore the distribution of high velocity regions for the standard spacer is very 
heterogeneous. The trend is opposite in case of standard spacer compared to the turbospacer.

295 Velocity magnitude increases as the fluid approach the membrane surface, whereas for turbospacer it reduces while moving closer to the membrane surface. Although the flow is also unsteady, the amount of perturbation generated by the standard spacer is quite less compared to the turbospacer (See the attached video). Thus, it is evident that much higher turbulence is achieved inside a spacer cell of turbospacer compared to the standard spacer, and therefore, it should effectively minimize the foulants deposition on the membrane surface and improve flux recovery.

In the filtration systems, the membrane fouling characteristics are not only a function of membrane material and its affinity to different types of bacteria and foulants but also depend on the hydrodynamics shear stress experienced at the surface of the membrane [41, 42]. Therefore, it is pivotal to understand the shear stress distribution to gauge hydrodynamics influence on fouling. Fig. 3 shows the computational shear stress distribution on the bottom wall of the standard spacer and the turbospacer at $Q_{F}=173$ and $250 \mathrm{~mL} / \mathrm{min}$ flowrates. At the initial stage, when the rotor blades just start moving, shear stress values are higher under the rotor (see the attached movie). As time progress, and the hydrodynamics field quickly transits to the turbulent regime which results in fluctuating shear stress on the membrane surface in a range of $2-13 \mathrm{~N} / \mathrm{m}^{2}$ for $173 \mathrm{~mL} / \mathrm{min}$ and between 2 and $20 \mathrm{~N} / \mathrm{m}^{2}$ for $250 \mathrm{~mL} / \mathrm{min}$ case. This fluctuating shear stress not only provides a hostile environment for the (bio)fouling attachment but also prevents any further growth. On the other hand, a high constant (not effected by flow unsteadiness) shear stress $\left(\sim 40 \mathrm{~N} / \mathrm{m}^{2}\right.$ and $\sim 50 \mathrm{~N} / \mathrm{m}^{2}$ at $173 \mathrm{~mL} / \mathrm{min}$ for 250 $\mathrm{mL} / \mathrm{min}$, respectively) is visible under the filament (at the constriction zone) at all times for the case of standard spacer. High shear stresses at the constriction zones are known to produce

317 faster attachment of (bio)foulants under the filament resulting in fouled membrane surface later 

the flow is unsteady, therefore, fluctuation in shear stress is also visible.

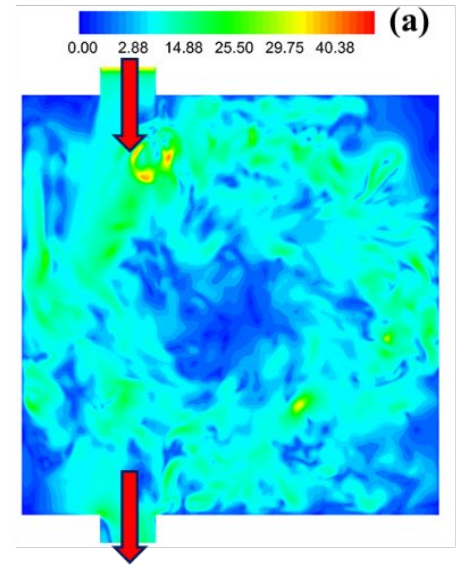

(b)

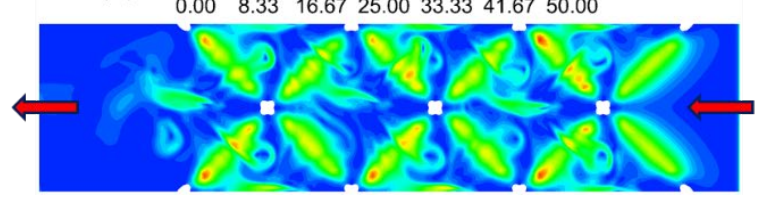

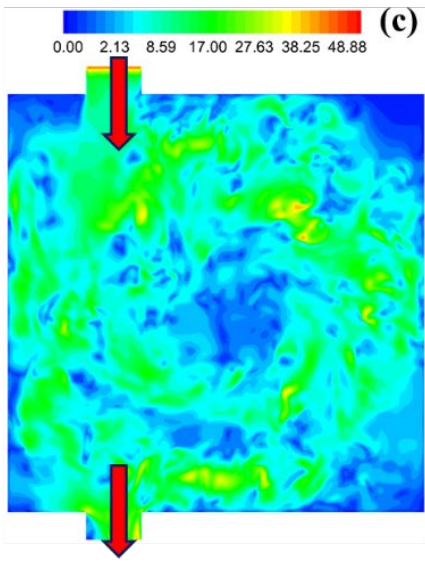

(d)

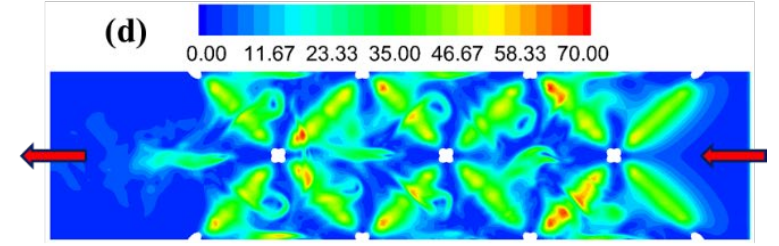

Fig. 3. Theoretically computed shear stress distribution on the bottom wall of the channel for turbospacer and standard spacer. Top row shows the shear stress for turbospacer at (a) $Q_{F}=$ 173 and (c) $250 \mathrm{~mL} / \mathrm{min}$ inlet flowrates. Shear stress using standard spacer is presented below for the flowrates (b and $d)$.

However, these fluctuations and vortex breakdown in standard spacer appear much smaller compared to the turbospacer. As expected, the magnitude and fluctuations of shear stress are more for higher flowrate $\left(Q_{F}=250 \mathrm{~mL} / \mathrm{min}\right)$ then the lower flowrate $\left(Q_{F}=173 \mathrm{~mL} / \mathrm{min}\right)$, therefore, higher fouling is predicted for lower flowrate in case of standard spacers. Thus, the current computational findings indicate that the proposed turbospacer should perform much superiorly than the standard spacer of similar thickness in terms of energy consumption, permeate flux, and in fouling mitigation. 


\subsection{Performances of the feed spacers in a filtration system}

334 Performances of the membrane filtration process were further experimentally investigated to 335 observe the effects of the feed channel hydrodynamics due to the rotation of the turbospacer 336 on the fouling accumulation, pressure drop, flux behavior, and energy consumption. These 337 experiments were conducted at two different feed solution inlet flowrates $(173 \mathrm{~mL} / \mathrm{min}$ and $338250 \mathrm{~mL} / \mathrm{min}$ ) to compare the performance of the conceptual turbospacer design with the 339 standard spacer at different operating conditions.

\subsubsection{Membrane fouling}

341 Images of the foulant layer accumulated over the membrane surface after the filtration achieved

342 its steady state (48 h) were captured in-situ by an OCT device at the same location ( $22 \mathrm{~mm}$ 343 apart from the first filament cell inlet) on the membrane surface for the turbospacer and the 344 standard spacer as shown in Table 1 (top view of turbospacer). Fig. 5 shows the OCT images 345 of the fouling behaviors for the turbospacer and the standard spacer at $173 \mathrm{~mL} / \mathrm{min}$ and 250

$346 \mathrm{~mL} / \mathrm{min}$ inlet flowrates. These images exhibit the membrane active layer, support layer, and 347 the accumulated fouling layer. 


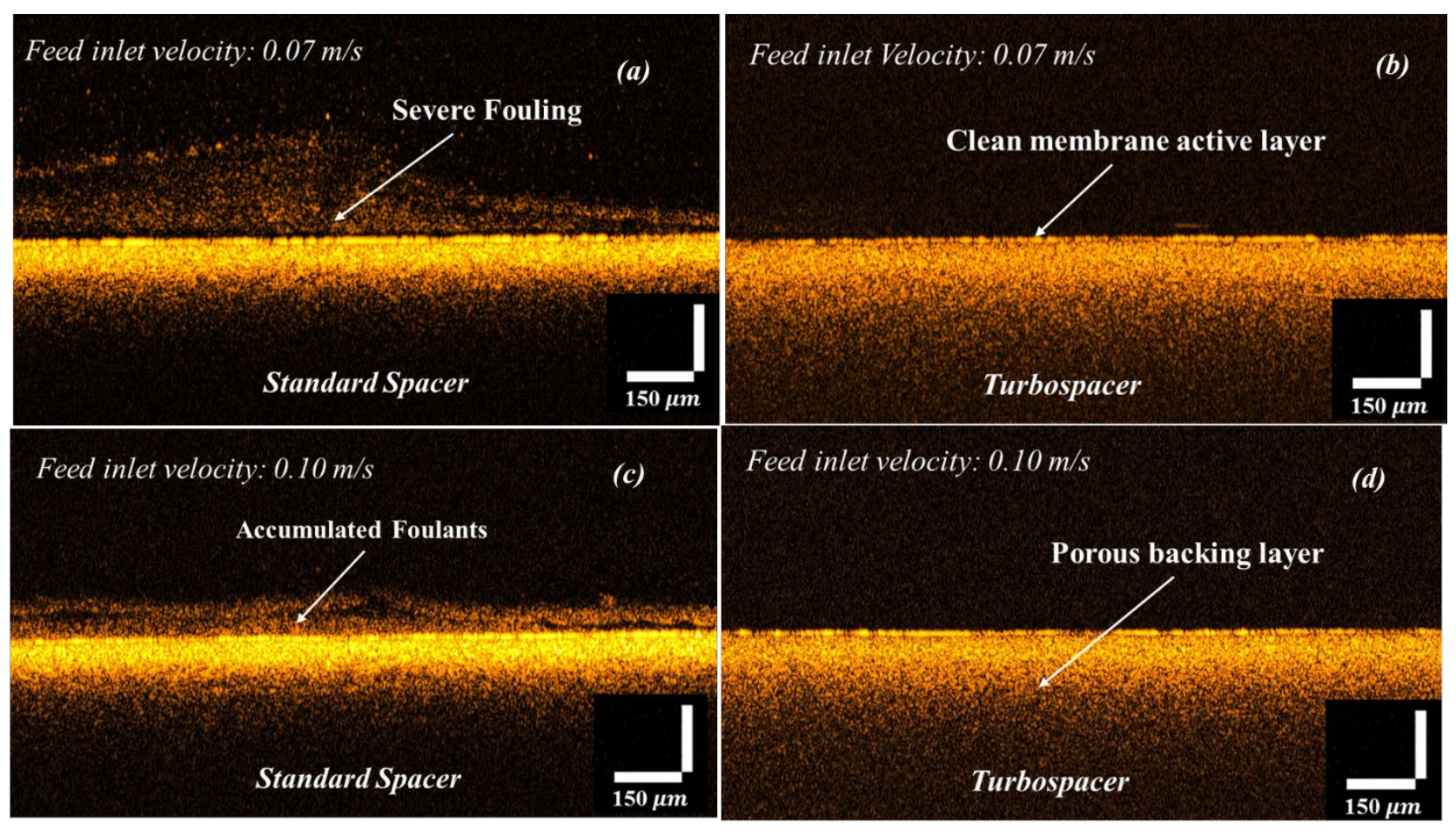

349 Fig. 5. OCT images of the accumulated foulants on the membrane surface at $173 \mathrm{~mL} / \mathrm{min}$ and $350250 \mathrm{~mL} / \mathrm{min}$ feed solution inlet velocities for (a, c) standard spacer and (b,d) turbospacer after $35148 \mathrm{~h}$ of operation.

352 It can be seen that the turbospacer significantly restrained the fouling growth at any flowrate as compared to the standard spacer. At $173 \mathrm{~mL} / \mathrm{min}$ inlet flowrate, the membrane surface observed to be clean for the turbospacer as a result of very high fluid unsteadiness and uniformly distributed perturbed shear stress across the channel (as shown in Fig. 1 and 3) which did not allow the foulant particles to settle over the membrane surface. In contrast, the standard spacer accumulated $179 \pm 53 \mu \mathrm{m}$ thick fouling layer over the membrane surface (Fig. 5(a)) for the same flowrate. High shear stress on membrane surface under the filament (constriction zone) account for higher bacterial attachments and subsequent lower fluid velocity (Fig. 2) and shear stress (Fig. 3) in the central region of the spacer cell resulted in the attachment and growth of biofilm to cause more complex fouling. At a higher inlet flowrate of $173 \mathrm{~mL} / \mathrm{min}$, the fouling layer thickness reduced to $90 \pm 8 \mu \mathrm{m}$ when the standard spacer was used, whereas no accumulation of foulants was found for the turbospacer. Fluid flow unsteadiness enhanced for 
both spacers when the feed inlet flowrate was increased (according to Fig. 1 and 2) which contributed to the reduction in fouling effects.

\subsubsection{Feed channel pressure drop}

367 Fig. 6 compares the average fluid pressure drop across the filtration cell with the standard 368 spacer and the proposed turbospacer during the filtration process. Mean values of the initial 369 pressure drop (measured at the beginning of the filtration) and the final pressure drop 370 (measured at the end of these experiments) were considered as average pressure drop in this 371 study. At $173 \mathrm{~mL} / \mathrm{min}$ inlet flowrate, $130 \mathrm{mbar}$ average pressure drop was found for the 372 standard spacer, whereas only 30 mbar pressured drop was recorded at the same flowrate when 373 the turbospacer was used. Large openings through the filaments, large filament spacing, less 374 accumulation of foulants in the channel, and the reduced drag force due to the rotation of the turbines contributed to almost four folds reduction in average pressure drop using the turbospacer. 


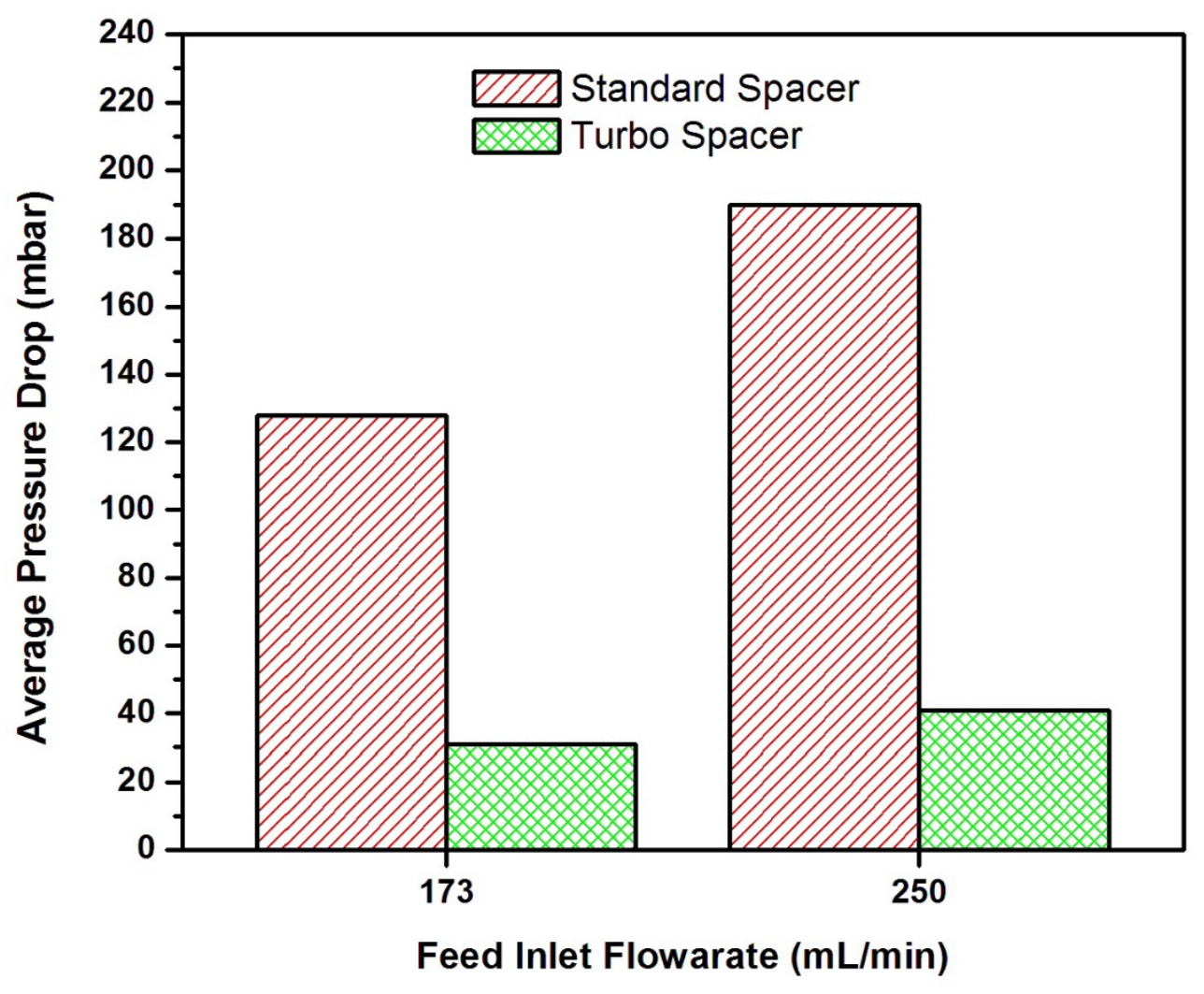

379 Fig. 6. Comparison of experimentally measured average pressure drop across the filtration cell

380 for the standard spacer and turbospacer at $Q_{F}=173 \mathrm{~mL} / \mathrm{min}$ and $Q_{F}=250 \mathrm{~mL} / \mathrm{min}$.

381 On the other hand, the combined effects of more foulants accumulation and excessive 382 obstruction in the channel cause a higher pressure drop for the standard spacer. At a higher feed

383 solution flowrate of $250 \mathrm{~mL} / \mathrm{min}$, this trend remained almost similar, where pressure drops for

384 both spacers increased. At this flowrate, pressure drops for the standard spacer and the 385 turbospacer were 190 and 40 mbar, respectively.

\section{$386 \quad 3.2 .3$. Flux behaviors of the spacers}

387 As explained in the experimental setup and operating conditions section, transient flux 388 behaviors of the standard spacer and the turbospacer were compared in terms of specific flux by relating the pressure drop and the permeate flux. 

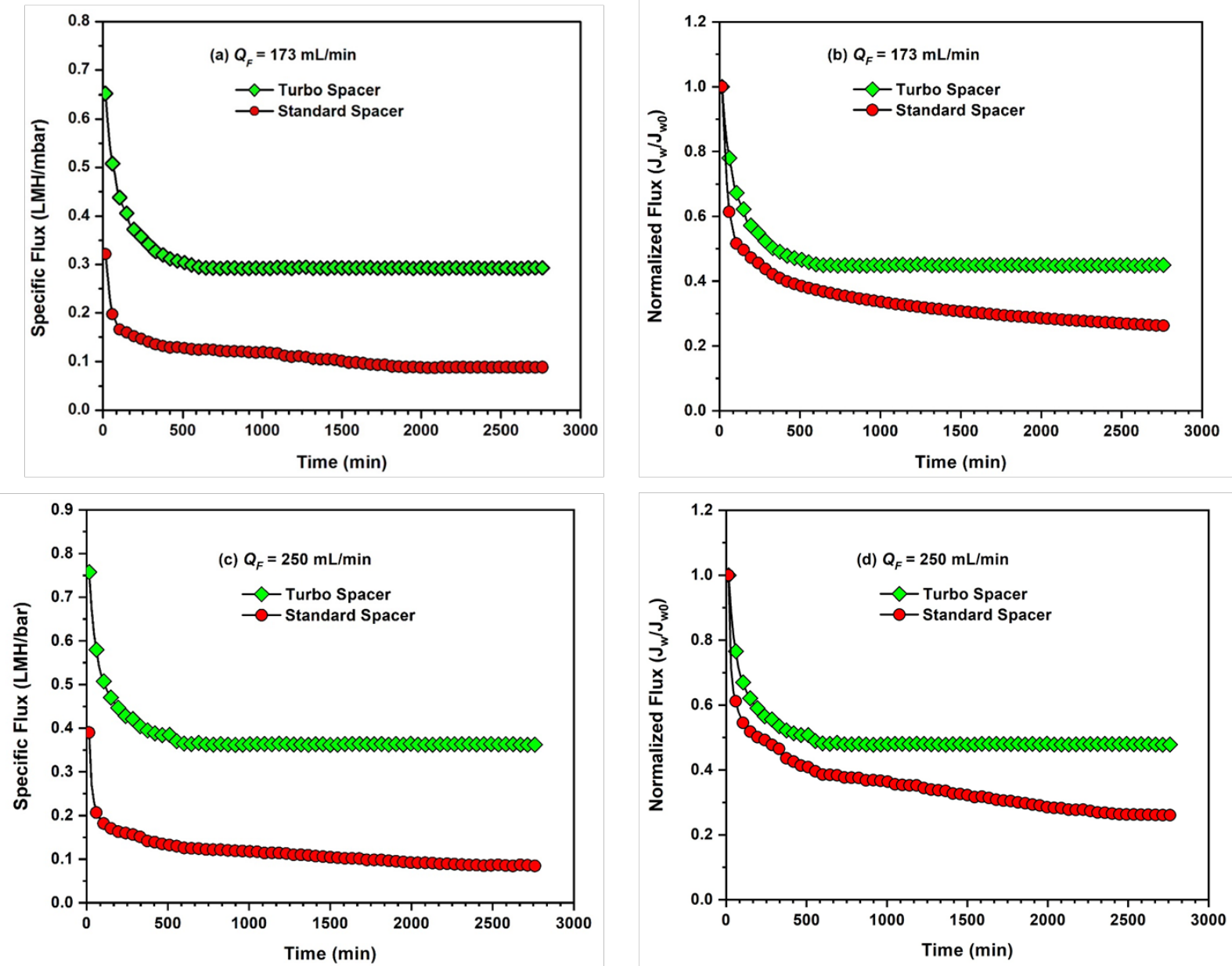

391 Fig. 7. Experimentally measured transient specific and normalized flux behaviour of the

392 filtration system at (a, b) $173 \mathrm{~mL} / \mathrm{min}$ and (c, d) $250 \mathrm{~mL} / \mathrm{min}$ for the turbospacer and the 393 standard spacer.

394 Fig. 7 describes the decline of the specific flux for the turbospacer and the standard spacer as 395 a function of time at $173 \mathrm{~mL} / \mathrm{min}$ and $250 \mathrm{~mL} / \mathrm{min}$. At any flowrate, when the standard spacer 396 was used, specific flux was drastically reduced initially (up to $100 \mathrm{~min}$ ) and then declined at a 397 much lower rate to reach a steady state after about 2000 min. In comparison, the specific flux 398 declined for a longer time (about $500 \mathrm{~min}$ ) but reached steady state faster (by $800 \mathrm{~min}$ ) when 399 the turbospacer was used. Initial longer flux decline period for the turbospacer was attributed 400 to the turbulence created by the spacer which delayed the pore blocking and fouling 401 accumulation on the membrane surface. However, the specific flux at steady state for the 402 standard spacer was $0.1 \mathrm{LMH} / \mathrm{mbar}$ of pressure drop at the feed solution inlet flowrate of 173 
$\mathrm{mL} / \mathrm{min}$, whereas the specific flux increased about 3 times $(0.3 \mathrm{LMH} / \mathrm{mbar})$ at the same

404 flowrate when the turbospacer was used. Lower pressure drop and less fouling accumulation in the feed channel resulted in higher specific flux for the turbospacer fitted with the UF membrane. The trend of the specific flux enhancement using the turbospacer remained almost

407 similar at a higher flowrate. At $250 \mathrm{~mL} / \mathrm{min}$ the specific flux for the standard spacer and the turbospacer was $0.08 \mathrm{LMH} / \mathrm{mbar}$ and $0.36 \mathrm{LMH} / \mathrm{mbar}$, respectively.

Fig. 7(b) and 7(d) compare the transient normalized water flux for the turbospacer and the standard spacer at $173 \mathrm{~mL} / \mathrm{min}$ and $250 \mathrm{~mL} / \mathrm{min}$ respectively. It can be seen from both figure that the normalized flux decline $\left(J_{w} / J_{w 0}\right)$ for the standard spacer was almost double compared to the turbospacer. At $173 \mathrm{~mL} / \mathrm{min}$, water flux declined to $45 \%$ of its initial value for turbospacer and reached a steady state. In contrast, water flux using the standard spacer dropped to $27 \%$ of its initial value after $48 \mathrm{~h}$ of filtration experiment (Fig. 7 (b)). At a higher flowrate of $250 \mathrm{~mL} / \mathrm{min}$, the trends remain almost similar (Fig. 7(d)).

\subsubsection{Comparison of energy consumption}

417 Specific energy consumption is one of the most important parameters to compare the

418 performance of the newly designed spacers. In this study, feed solution flowrates, final pressure 419 drops, and steady state fluxes were considered for the calculation of the specific energy consumption. Fig. 8 exhibits the specific energy consumption of the membrane filtration system for the designed turbospacer and the standard spacer. At $173 \mathrm{~mL} / \mathrm{min}$, specific energy consumption of the system using the standard spacer was $1.2 \mathrm{kWh} / \mathrm{m}^{3}$ where the final pressure drop across the test cell was 40 mbar. At the same flowrate, specific energy consumption using the turbospacer $\left(0.50 \mathrm{kWh} / \mathrm{m}^{3}\right)$ was about 2.5 times lower than the standard spacer when the final pressure drop was found to be 14 mbar. Reduced fouling effects on the membrane surface (as shown in Fig. 5) in case of turbospacer augmented the mass transport through the membrane at the same transmembrane pressure. In addition to this, lower resistance to the fluid flow in 
the channel minimizes the pressure drop across the test cell. Therefore, the effects of better

429 permeation and lower pressure drop reduced the specific energy consumption for the turbospacer. However, the energy consumption for the standard spacers increased when the

431 feed solution inlet flowrate was increased to $250 \mathrm{~mL} / \mathrm{min}$. But the energy consumption 432 remained almost similar when the trubopromoter was used. Specific energy consumption for 433 the standard spacer increased to $1.8 \mathrm{kWh} / \mathrm{m}^{3}$ from $1.2 \mathrm{kWh} / \mathrm{m}^{3}$ as the pressure drop increased 434 at the higher flowrate. On the other hand, for the turbospacer membrane surface remained clean at $250 \mathrm{~mL} / \mathrm{min}$ flowrate but the pressure drop across the test cell slightly increased.

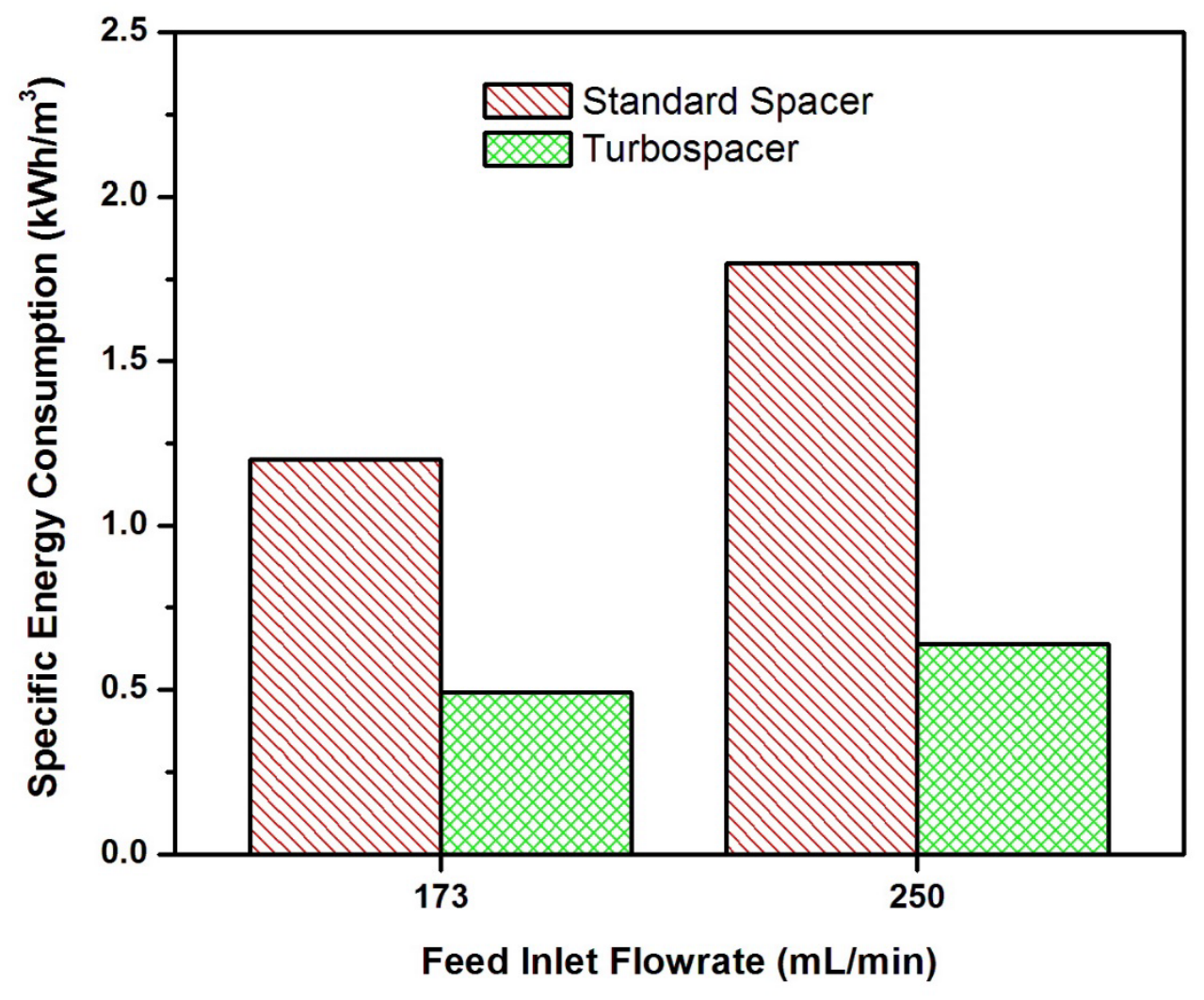

Fig. 8. Comparison of the experimentally investigated specific energy consumption for the standards spacer and turbospacer at $173 \mathrm{~mL} / \mathrm{min}$ and $250 \mathrm{~mL} / \mathrm{min}$.

As a result, the specific energy consumption slightly increased from $0.50 \mathrm{kWh} / \mathrm{m}^{3}$ to 0.65 $\mathrm{kWh} / \mathrm{m}^{3}$. However, experimentally measured specific energy consumption values of the labscale UF setup in the present study were very high in comparison with a full-scale UF system, 
442 which was mostly operated under dead-end filtration mode and consumed less energy [43]. But

443 these performance values were only employed to compare the spacers when the operating 444 parameters remained the same.

\section{Conclusions}

This proof of concept study demonstrated the design of a novel dynamic turbospacer to exploit the kinetic energy of the flowing feed solution to enhance the flow turbulence in plate and frame membrane module. 3D direct numerical simulation was conducted to theoretically analyze the fluid flow behaviour in the feed channel using the proposed turbospacer and a nonwoven symmetric standard spacer. Moreover, the performance of the standard spacer and the turbospacer in a low pressure membrane filtration process (UF) for the filtration of seawater were experimentally investigated using their 3D printed prototypes. The major findings of the studies are listed below:

- Numerical results revealed that the turbospacer facilitated a homogenous distribution of high velocity and shear stress in the channel and produced a completely turbulent flow through the fluctuating shear stress and vortex breakdown. In contrast, the standard spacer exhibited high velocity and shear stress only under the filaments with a very small effect of flow unsteadiness.

- The proposed turbospacer achieved more than 3 times higher specific flux in comparison with the standard spacer at $173 \mathrm{~mL} / \mathrm{min}$ inlet flowrate when the Reynolds number is 160 .

- About 2.5 folds lower specific energy consumption was obtained for the turbospacer in comparison with the standard spacer when a synthetic seawater with high fouling potential was filtered by using a UF membrane. 
- OCT images of the foulant layer on the membrane surface showed that the turbospacer minimized the accumulation of foulants very efficiently.

467

468

469

470

471

472

473

474

475

476

477

478

479

480

481

482

483

484

485

486

The prototype of the turbospacer used in this proof of concept study showed promising performance in short term filtration experiments with harsh fouling conditions. For more realistic applications, the spacer can be tested for longer term experiments with different foulant concentrations. Moreover, the geometry and arrangements of the filaments and rotors, fluid flow path, and cleaning strategies can be further optimized.

\section{CRediT authorship contribution statement}

Syed Muztuza Ali: Conceptualization, Data curation, Formal analysis, Investigation, Methodology, Validation, Writing - original draft. Adnan Qamar: Methodology, Data curation, Formal analysis, Writing - original draft, Writing - review \& editing; Sherub Phuntsho: Writing - review \& editing. Noreddine Ghaffour: Validation, Writing - review \& editing; Johannes S. Vrouwenvelder: Validation, Writing - review \& editing; Hokyong

Shon: Supervision, Project administration, Resources, Funding acquisition, Validation, Writing - review \& editing.

\section{Acknowledgments}

The research reported in this paper was supported by King Abdullah University of Science and Technology (KAUST), Saudi Arabia. The authors acknowledge support from the Water Desalination and Reuse Center (WDRC) staff and KAUST Supercomputing Laboratory to fabricate the 3-D printed spacers and perform the experimental work. This research was supported by the Qatar National Research Fund under its National Priorities Research Program (NPRP 12S-0227-190166). 
490 [1] G. Amy, N. Ghaffour, Z. Li, L. Francis, R.V. Linares, T. Missimer, S. Lattemann, Membrane-based seawater desalination: Present and future prospects, Desalination, 401 (2017) 16-21.

[2] K. Park, J. Kim, D.R. Yang, S. Hong, Towards a low-energy seawater reverse osmosis desalination plant: A review and theoretical analysis for future directions, Journal of Membrane Science, 595 (2020) 117607.

495 [3] M. Qasim, M. Badrelzaman, N.N. Darwish, N.A. Darwish, N. Hilal, Reverse osmosis desalination: A state-of-the-art review, Desalination, 459 (2019) 59-104.

[4] H. Gu, A. Rahardianto, L.X. Gao, X.P. Caro, J. Giralt, R. Rallo, P.D. Christofides, Y. Cohen, Fouling indicators for field monitoring the effectiveness of operational strategies of ultrafiltration as pretreatment for seawater desalination, Desalination, 431 (2018) 86-99.

[5] M. Badruzzaman, N. Voutchkov, L. Weinrich, J.G. Jacangelo, Selection of pretreatment technologies for seawater reverse osmosis plants: A review, Desalination, 449 (2019) 78-91.

[6] S. Li, S.G.J. Heijman, J.Q.J.C. Verberk, G.L. Amy, J.C. van Dijk, Seawater ultrafiltration fouling control: Backwashing with demineralized water/SWRO permeate, Separation and Purification Technology, 98 (2012) 327-336.

[7] S.S. Bucs, R. Valladares Linares, J.O. Marston, A.I. Radu, J.S. Vrouwenvelder, C. Picioreanu, Experimental and numerical characterization of the water flow in spacer-filled channels of spiral-wound membranes, Water Research, 87 (2015) 299-310.

[8] P. Sousa, A. Soares, E. Monteiro, A. Rouboa, A CFD study of the hydrodynamics in a desalination membrane filled with spacers, Desalination, 349 (2014) 22-30.

[9] J. Amigo, R. Urtubia, F. Suárez, Exploring the interactions between hydrodynamics and fouling in membrane distillation systems - A multiscale approach using CFD, Desalination, 444 (2018) 63-74.

[10] J. Schwinge, D.E. Wiley, D.F. Fletcher, Simulation of unsteady flow and vortex shedding for narrow spacer-filled channels, Industrial and Engineering Chemistry Research, 42 (2003) 4962-4977.

[11] A.J. Karabelas, C.P. Koutsou, D.C. Sioutopoulos, Comprehensive performance assessment of spacers in spiral-wound membrane modules accounting for compressibility effects, Journal of Membrane Science, 549 (2018) 602-615.

[12] J. Schwinge, P.R. Neal, D.E. Wiley, D.F. Fletcher, A.G. Fane, Spiral wound modules and spacers: Review and analysis, Journal of Membrane Science, 242 (2004) 129-153.

[13] H. Thiess, M. Leuthold, U. Grummert, J. Strube, Module design for ultrafiltration in biotechnology: Hydraulic analysis and statistical modeling, Journal of Membrane Science, 540 (2017) 440-453.

[14] A.R. Da Costa, A.G. Fane, Net-Type Spacers: Effect of Configuration on Fluid Flow Path and Ultrafiltration Flux, Industrial and Engineering Chemistry Research, 33 (1994) 1845-1851.

[15] A.L. Ahmad, K.K. Lau, M.Z. Abu Bakar, Impact of different spacer filament geometries on concentration polarization control in narrow membrane channel, Journal of Membrane Science, 262 (2005) 138-152.

[16] K.K. Lau, M.Z. Abu Bakar, A.L. Ahmad, T. Murugesan, Effect of Feed Spacer Mesh Length Ratio on Unsteady Hydrodynamics in 2D Spiral Wound Membrane (SWM) Channel, Industrial \& Engineering Chemistry Research, 49 (2010) 5834-5845.

[17] H.S. Abid, D.J. Johnson, R. Hashaikeh, N. Hilal, A review of efforts to reduce membrane fouling by control of feed spacer characteristics, Desalination, 420 (2017) 384-402.

[18] B. Gu, C.S. Adjiman, X.Y. Xu, The effect of feed spacer geometry on membrane performance and concentration polarisation based on 3D CFD simulations, Journal of Membrane Science, 527 (2017) 78-91.

[19] A. Qamar, S. Bucs, C. Picioreanu, J. Vrouwenvelder, N. Ghaffour, Hydrodynamic flow transition dynamics in a spacer filled filtration channel using direct numerical simulation, Journal of Membrane Science, 590 (2019) 117264.

[20] M. Park, J.H. Kim, Numerical analysis of spacer impacts on forward osmosis membrane process using concentration polarization index, Journal of Membrane Science, 427 (2013) 10-20. 
[21] A. Qamar, R. Samtaney, J.L. Bull, Pulsatility role in cylinder flow dynamics at low Reynolds number, Physics of Fluids, 24 (2012) 081701. membrane (SWM) module performance, Journal of Membrane Science, 488 (2015) 129-142.

[23] C. Fritzmann, M. Wiese, T. Melin, M. Wessling, Helically microstructured spacers improve mass transfer and fractionation selectivity in ultrafiltration, Journal of Membrane Science, 463 (2014) 41-48. [24] S. Kerdi, A. Qamar, J.S. Vrouwenvelder, N. Ghaffour, Fouling resilient perforated feed spacers for membrane filtration, Water Research, 140 (2018) 211-219.

[25] N. Sreedhar, N. Thomas, O. Al-Ketan, R. Rowshan, H. Hernandez, R.K. Abu Al-Rub, H.A. Arafat, 3D printed feed spacers based on triply periodic minimal surfaces for flux enhancement and biofouling mitigation in RO and UF, Desalination, 425 (2018) 12-21.

[26] S. Kerdi, A. Qamar, A. Alpatova, J.S. Vrouwenvelder, N. Ghaffour, Membrane filtration performance enhancement and biofouling mitigation using symmetric spacers with helical filaments, Desalination, 484 (2020) 114454.

[27] S.M. Ali, A. Qamar, S. Kerdi, S. Phuntsho, J.S. Vrouwenvelder, N. Ghaffour, H.K. Shon, Energy efficient 3D printed column type feed spacer for membrane filtration, Water Research, 164 (2019) 114961.

[28] W. Li, K.K. Chen, Y.-N. Wang, W.B. Krantz, A.G. Fane, C.Y. Tang, A conceptual design of spacers with hairy structures for membrane processes, Journal of Membrane Science, 510 (2016) 314325.

[29] M. Cheryan, Ultrafiltration and Microfiltration Handbook, 2nd ed., Taylor and Francis Group, Florida, USA, 1998.

[30] C. Fritzmann, M. Hausmann, M. Wiese, M. Wessling, T. Melin, Microstructured spacers for submerged membrane filtration systems, Journal of Membrane Science, 446 (2013) 189-200.

[31] J. Liu, Z. Liu, X. Xu, F. Liu, Saw-tooth spacer for membrane filtration: Hydrodynamic investigation by PIV and filtration experiment validation, Chemical Engineering and Processing: Process Intensification, 91 (2015) 23-34.

[32] J. Liu, A. Iranshahi, Y. Lou, G. Lipscomb, Static mixing spacers for spiral wound modules, Journal of Membrane Science, 442 (2013) 140-148.

[33] W. Zhang, W. Cheng, W. Gao, A. Qamar, R. Samtaney, Geometrical effects on the airfoil flow separation and transition, Computers and Fluids, 116 (2015) 60-73.

[34] A. Siddiqui, N. Farhat, S.S. Bucs, R.V. Linares, C. Picioreanu, J.C. Kruithof, M.C.M. Van Loosdrecht, J. Kidwell, J.S. Vrouwenvelder, Development and characterization of 3D-printed feed spacers for spiral wound membrane systems, Water Research, 91 (2016) 55-67.

[35] A. Saeed, R. Vuthaluru, Y. Yang, H.B. Vuthaluru, Effect of feed spacer arrangement on flow dynamics through spacer filled membranes, Desalination, 285 (2012) 163-169.

[36] I. ANSYS, ANSYS Fluent Theory Guide, Southpointe, 2600 ANSYS Drive, Canonsburg, PA 15317, 2016.

[37] A. Qamar, N. Hasan, S. Sanghi, A New Spatial Discretization Strategy of the Convective Flux Term for the Hyperbolic Conservation Laws, Engineering Applications of Computational Fluid Mechanics, 4 (2010) 593-611.

[38] Y. Gao, S. Haavisto, W. Li, C.Y. Tang, J. Salmela, A.G. Fane, Novel Approach To Characterizing the Growth of a Fouling Layer during Membrane Filtration via Optical Coherence Tomography, Environmental Science \& Technology, 48 (2014) 14273-14281.

[39] S. Kerdi, A. Qamar, A. Alpatova, N. Ghaffour, An in-situ technique for the direct structural characterization of biofouling in membrane filtration, Journal of Membrane Science, 583 (2019) 81-92. [40] N. Sreedhar, N. Thomas, O. Al-Ketan, R. Rowshan, H.H. Hernandez, R.K. Abu Al-Rub, H.A. Arafat, Mass transfer analysis of ultrafiltration using spacers based on triply periodic minimal surfaces: Effects of spacer design, directionality and voidage, Journal of Membrane Science, 561 (2018) 89-98. [41] S. Lecuyer, R. Rusconi, Y. Shen, A. Forsyth, H. Vlamakis, R. Kolter, H.A. Stone, Shear stress increases the residence time of adhesion of Pseudomonas aeruginosa, Biophysical Journal, 100 (2011) 341-350.

[42] T. Saur, E. Morin, F. Habouzit, N. Bernet, R. Escudie, Impact of wall shear stress on initial bacterial adhesion in rotating annular reactor, PLoS ONE, 12 (2017) e0172113. 
[43] S.K. Al-Mashharawi, N. Ghaffour, M. Al-Ghamdi, G.L. Amy, Evaluating the efficiency of different microfiltration and ultrafiltration membranes used as pretreatment for Red Sea water reverse osmosis desalination, Desalination and Water Treatment, 51 (2013) 617-626. 